\title{
Genetics of sex-ratio variation inferred from parent-offspring regressions and sib correlations in the apple snail Pomacea canaliculata
}

\author{
Y Yusa \\ National Agricultural Research Center for Kyushu Okinawa Region, Nishigoshi, Kumamoto 861-1192, Japan
}

\begin{abstract}
The brood sex ratio in the apple snail Pomacea canaliculata varies almost continuously from all male to all female, but the population sex ratio is nearly $1: 1$. In this study, regressions of the offspring sex ratio on the sex ratios of the parents' siblings as well as correlations in the brood sex ratios between sisters or brothers were investigated, in order to infer the genetic system that produces the sex-ratio pattern. There were significant positive relationships between the offspring sex ratio and the sex ratio of the mother's siblings (slope $=0.28$ ), and between the offspring sex ratios of two sisters $(r=0.41)$. On the other hand, the father-offspring
\end{abstract}

Keywords: inheritance; nuclear gene; sex determination; sex-determining gene; zygotic control; gastropod

regression (slope $=0.10$ ), and the correlations between two brothers $(r=-0.13)$ or between the brother and the sister $(r=0.17)$ were not significant. These patterns differed from predictions using typical cytoplasmic sex factors, sex-ratio genes or sex-determining polygenes. Thus, the results suggest the involvement of either a small number of sexdetermining genes or a more complicated system such as sex-ratio or sex-determining polygenes that act nonadditively.

Heredity (2006) 96, 100-105. doi:10.1038/sj.hdy.6800758; published online 28 September 2005

\section{Introduction}

The genetics of sex-ratio variation have important implications for the evolution of the sex ratio for two reasons. First, additive genetic variance is required for the evolution of any trait, including the sex ratio (Fisher, 1930). Second, the genetics may have a direct influence on the sex ratio. For instance, cytoplasmic sex factors, such as the symbiotic bacterium Wolbachia, often behave selfishly and cause female-biased sex ratios of their host species, since they can only be transmitted through females (Stouthamer et al, 2002). The opposite effect (male-biased sex ratios) is known to occur for meiotic drive genes on the Y-or B-chromosomes (Stouthamer et al, 2002).

There is also a growing interest in the diversity of the genetics of sex-ratio variance or sex determination (Bull, 1983; Werren and Beukeboom, 1998). For instance, both male heterogamety (XY sex determination) and female heterogamety (ZW) lead to 1:1 population sex ratios, even without the frequency-dependent selection proposed by Fisher (1930). A more complicated system has been reported in a mite (Procter, 1996) and a rhizocephalan barnacle (Yanagimachi, 1961), in which two types of females, producing all sons or all daughters (monogeny), are determined genetically. This system will also ensure 1:1 population sex ratios if the genetic factors segregate with a probability of 0.5 , although brood sex ratios in terms of the proportion of males are 0 or 1 .

Correspondence: Y Yusa. Current address: Faculty of Science, Nara Women's University, Kitauoya-Nishi, Nara 630-8506, Japan.

E-mail: yusa@cc.nara-wu.ac.jp

Received 1 May 2005; accepted 15 August 2005; published online 28 September 2005
However, the genetic mechanisms of sex ratio variation remain unknown in most organisms. Currently, there is a gap in our knowledge between evolutionary ecology studying the adaptive significance of sex-ratio variation (for a recent example, see Hardy, 2002) and genetics studying its mechanisms (Bull, 1983; Werren and Beukeboom, 1998).

Genetic factors that influence sex-ratio variation can be distinguished in two ways (Bull, 1983; Werren and Beukeboom, 1998; Voordouw and Anholt, 2002). First, the genetic factors are either parental sex-ratio genes (including parental-effect sex determiners; Werren and Beukeboom, 1998) or zygotic sex-determining genes. Parental sex-ratio genes are those that control the offspring sex ratios, for instance, by affecting the fertilization success of X-carrying sperm (Werren and Beukeboom, 1998) either paternally or maternally. Zygotic sex-determining genes are genes that are translated in the zygote and determine its sex. Second, if they are zygotic, the sex-determining genetic factors may be either nuclear or cytoplasmic (Werren and Beukeboom, 1998; Stouthamer et al, 2002). As already stated, cytoplasmic factors are inherited maternally and often distort the host's sex ratio toward females. Simple $\mathrm{XY}$ or ZW sex determinations are not considered here, since they do not produce greater variation of the sex ratio than expected under the binomial distribution. Models for the genetics of sex-ratio variation normally have postulated polygenes in the case of zygotic nuclear genes (Bulmer and Bull, 1982; Premoli et al, 1996; Voordouw and Anholt, 2002). However, it is doubtful whether typical polygenes, acting collectively without major genes, are commonly found. For instance, the sexratio variation reported in the polychaete Ophryotrocha 
labronica is not congruent with a simple polygene model (Premoli et al, 1996).

The apple snail Pomacea canaliculata (Lamarck) is a South American freshwater gastropod from the family Ampullariidae. The females lay egg masses above water, and the young snails hatch and fall into the water at 10-14 days. No parental care exists either before or after hatching. The brood sex ratio varies almost continuously from all male to all female, depending on the mating pairs producing the brood (Yusa and Suzuki, 2003), yet the average sex ratios are almost 1:1 in all populations studied. Several environmental factors have been studied for their possible effects on the sex ratio, but no such effects have been detected (Yusa, 2004b). All these results suggest a unique genetic mechanism for the sex-ratio variation in $P$. canaliculata. Genetic studies of the sex-ratio variation are also important practically, since this snail is an invasive species and a serious rice pest (Cowie, 2002), and control methods are currently limited (Yusa, 2004a; Yusa et al, 2005).

In this paper, I addressed the genetic nature of the sexratio variation in $P$. canaliculata. Various family relationships were used, such as regressions of the offspring sex ratio on the sex ratios of the parents' siblings, and correlations in the offspring sex ratios between two sisters or two brothers. The results led to different regression or correlation coefficients. I further discuss three types of simple genetic systems that provide possible explanations for these results, namely cytoplasmic sex factors, nuclear sex-ratio genes and polygenic sex determination. None of these systems could explain the results, suggesting that the sex ratio variation is caused by either a more complicated genetic system or a small number of sex-determining genes.

\section{Materials and methods}

\section{Rearing of snails}

Immature snails of 13-19 $\mathrm{mm}$ shell height were collected in organic paddy fields in Shichijo Town, Kumamoto, southern Japan in July 2000. Their sex was identified by the presence or absence of the testis, as observed through the thin shell without dissection. Next, 116 heterosexual pairs were formed. Although female P. canaliculata can store sperm received from more than one male when they become mature (Yusa, 2004a), this pairing of immature snails ensured that the male in each pair sired all the offspring. The pairs were reared individually in small aquaria containing 21 of water under laboratory conditions of $25^{\circ} \mathrm{C}$ with 14-h light and 10-h dark photoperiods. Carp food pellets and a small amount of powdered oyster shell (as a calcium supply) were provided ad libitum, and the water was changed at least once a week. Further details of the rearing conditions were described in Yusa and Suzuki (2003) and Yusa (2004b).

When the female of the pair became mature and laid an egg mass, the mass was removed from the aquarium after it hardened (at least 2 days after egg laying), and allowed to hatch in a Petri dish. When the new hatchlings appeared, up to 40 individuals ( $F_{1}$ generation) were taken and reared in an outdoor 21 aquarium for more than 50 days (Yusa, 2004b). It has previously been shown that the rearing conditions, whether laboratory or outdoor, have no effect on the brood sex ratio (Yusa, 2004b). Subsequently, $F_{1}$ snails reaching $14 \mathrm{~mm}$ shell height were dissected and their sex was identified by directly inspecting the reproductive organs (the testis for males and the albumen gland for females). However, up to two males and two females (usually the largest individuals of each sex) in each brood were kept alive to produce $\mathrm{F}_{2}$ broods. Their sex was identified before pairing by observing the presence or absence of the testis through the shell, and later confirmed by either dissection or the production of fertilized eggs after pairing (see below). The brood sex ratio was defined as the proportion of males in a brood.

Each of the $F_{1}$ males and females was paired with a partner of the opposite sex from a different brood, without reference to their sex ratio ( $n=112$ pairs). Each pair was reared in a 21 aquarium in the laboratory as described above. When an egg mass was found in the aquarium, it was taken and reared until hatching. Subsequently, up to 40 hatchlings were reared from each $F_{1}$ pair to determine the $F_{2}$ sex ratio.

\section{Threshold model of sex determination}

The sex was assumed to be a threshold trait (Bulmer and Bull, 1982; Voordouw and Anholt, 2002; Kobayashi et al, 2003). In this case, the sex ratio is the proportion of males, whose trait underlying the sex determination exceeds a threshold (for simplicity, the underlying variable is scaled as male tendency). The underlying variable is normally distributed. Thus, the sex ratio of a brood can be translated into the position of a standardized normal curve of the underlying variable relative to the threshold (Bulmer and Bull, 1982; Falconer, 1989; Roff, 1997). To perform this, each sex ratio was transformed to the mean of the normal curve on the abscissa (' $m$ ' in Figure 18.1 in Falconer, 1989) relative to the threshold (set at 0 ). When the proportion is 0 or 1 , the mean of the curve becomes $-\infty$ or $\infty$, respectively. To avoid this, the minimum and maximum sex ratios were set to $0.0125(=0.5 / 40)$ and $0.9875(=39.5 / 40)$ for this analysis, and the corresponding $m$-values were calculated ( -2.24 and 2.24 , respectively).

\section{Statistical analyses}

To test whether the sex-ratio data deviated from the binomial distribution, a generalized linear model with binomial errors was applied, with the untransformed sex ratio (proportion of males) as the dependent variable and the identity of the brood as the independent variable (Wilson and Hardy, 2002).

For parent-offspring regressions, the sex ratio of the offspring (for instance, $\mathrm{SR}_{5}$ in Figure 1) was regressed to the sex ratio of their father's siblings $\left(\mathrm{SR}_{1}\right)$ or that of their mother's siblings $\left(\mathrm{SR}_{2}\right)$ using the least-squares regression method (Sokal and Rohlf, 1981). As explained in the previous section, the sex-ratio data were transformed to the underlying $m$-value.

The correlations (Pearson's $r$ ) in the offspring sex ratios between sisters $\left(\mathrm{SR}_{5}\right.$ and $\mathrm{SR}_{6}$ in Figure 1$)$ and between brothers $\left(\mathrm{SR}_{6}\right.$ and $\left.\mathrm{SR}_{7}\right)$ were calculated after $m$-transformation of the sex-ratio data. One of the two siblings (older or younger) was randomly allotted to the abscissa and the other to the ordinate, in order to avoid the possible effect that the older sibling tends to have a 


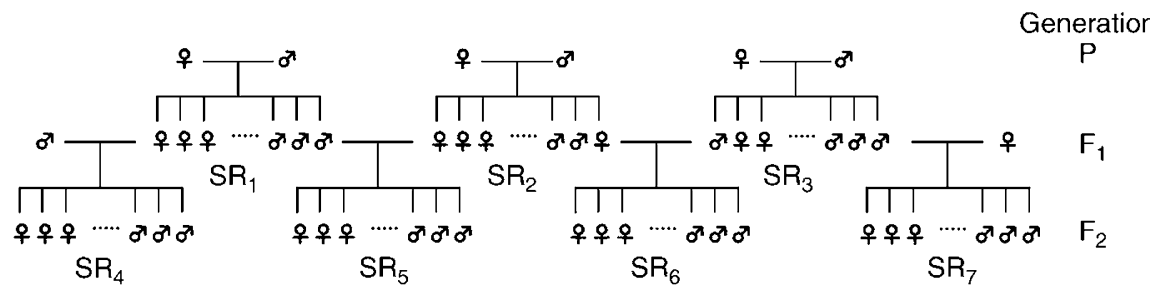

Figure 1 Experimental design showing the sex ratio analysis by parent-offspring regression and correlation between siblings. The sex ratio is shown as SR.

higher (or lower) offspring sex ratio. This randomization was replicated 100 times, and the average $r$-value was calculated. The $P$-value and standard error were calculated in the standard manner (Sokal and Rohlf, 1981) based on the average $r$-value.

In the case of brother-sister correlations, the average sex ratio for the two sisters (or two brothers) was used if there were two. In this case, the brood sex ratio of the brother (or the average of two brothers) was always allotted to the abscissa, and the ratio of the sister(s) to the ordinate. No randomization was conducted.

\section{Results}

Sex-ratio variation among $F_{1}$ and $F_{2}$ broods

The $F_{1}$ brood sex ratio was successfully obtained for 67 of the 116 pairs $(58 \%)$. After egg masses were laid and $F_{1}$ hatchlings were reared, their survival rate was fairly high (91 $\pm 11 \%$; untransformed mean $\pm \mathrm{SD}, n=67)$, with $35 \pm 5.2$ snails (range 21-40 snails) that could be sexed per brood. The brood sex ratio, in terms of the proportion of males within each brood, varied greatly from 0.00 (three pairs; largest brood was 0 males:40 females) to 0.97 (35 males:1 female). The sex-ratio variation was significantly greater than expected under binomial distribution $\left(\mathrm{df}=66, \chi^{2}=573.1, P<0.001\right)$. The overall sex ratio was $0.46 \pm 0.23$ (untransformed mean \pm SD).

The $\mathrm{F}_{2}$ brood sex ratio was successfully obtained for 87 of the $112 \mathrm{~F}_{1}$ pairs $(78 \%)$. The survival rate of the $\mathrm{F}_{1}$ broods was also high $(89 \pm 18 \%$; untransformed mean \pm SD, $n=87$ ), with $35 \pm 8.2$ snails (range $10-40$ snails) that could be sexed per brood. Again, the brood sex ratio varied greatly from 0.00 (0 males: 40 females) to 1.00 (40 males:0 females) and the sex-ratio variation was significantly greater than expected under binomial distribution $\left(d f=86, \chi^{2}=1134.6, P<0.001\right)$. The overall sex ratio was $0.49 \pm 0.28$ (untransformed mean \pm SD). These results confirm previous observations (Yusa and Suzuki, 2003; Yusa, 2004b) that although the brood sex ratio varies greatly, the population sex ratio is nearly 0.5 in this snail.

The $\mathrm{F}_{1}$ males and females were paired randomly in terms of the sex ratio of their siblings. Consequently, the correlation for the sex ratios between the male's siblings and the female's siblings was not significant $(n=87$, $r=-0.10, P=0.34$ after $m$-transformation).

\section{Parent-offspring regression}

The regression of the offspring $\left(\mathrm{F}_{2}\right)$ sex ratio on the sex ratio of the mother's siblings $\left(\mathrm{F}_{1}\right)$ was significantly positive (Figure 2a; $n=87$, slope $\pm \mathrm{SE}=0.28 \pm 0.13$,
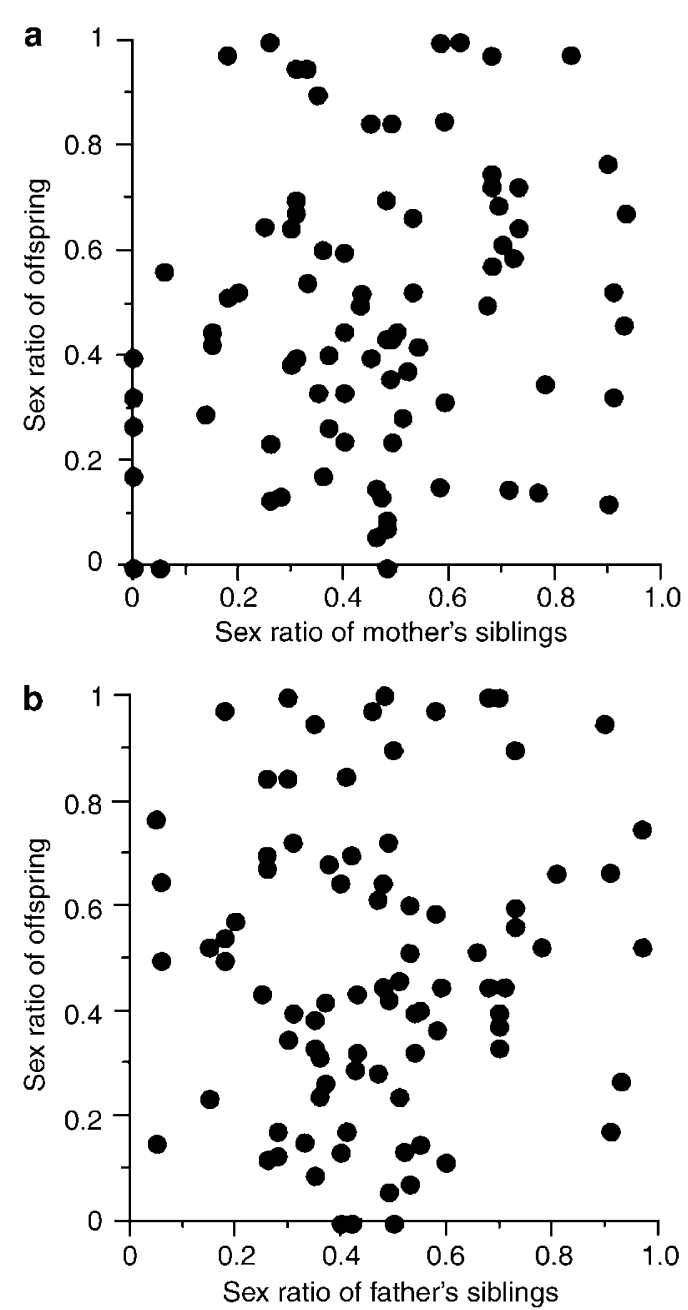

Figure 2 Sex-ratio (proportion of males) regression of offspring on (a) the mother's siblings and (b) the father's siblings.

$P<0.05)$ when the sex-ratio data were transformed to the underlying $m$-value.

On the other hand, the regression of the $\mathrm{F}_{2}$ sex ratio on the father's siblings was not significant (Figure 2b; $n=87$, slope $\pm \mathrm{SE}=0.10 \pm 0.16, P=0.51$ ).

\section{Sib correlation}

The correlation of the offspring $\left(\mathrm{F}_{2}\right)$ sex ratios between $\mathrm{F}_{1}$ sisters was significantly positive after $m$-transformation (Figure 3a; $n=29, r \pm \mathrm{SE}=0.41 \pm 0.18, P<0.05$ with 100 randomizations for the axes). 
On the other hand, there was no significant correlation of the offspring sex ratios between brothers after $m$ transformation (Figure $3 b ; n=30, r \pm S E=-0.13 \pm 0.19$, $P=0.51$ with 100 randomizations for the axes). The correlation of the offspring sex ratios between brothers and sisters was also not significant $(n=47, r=0.17$, $P=0.24)$.

\section{Discussion}

The results suggest that the highly variable brood sex ratios of $P$. canaliculata have a genetic basis, via two lines of evidence. First, there was a significant positive
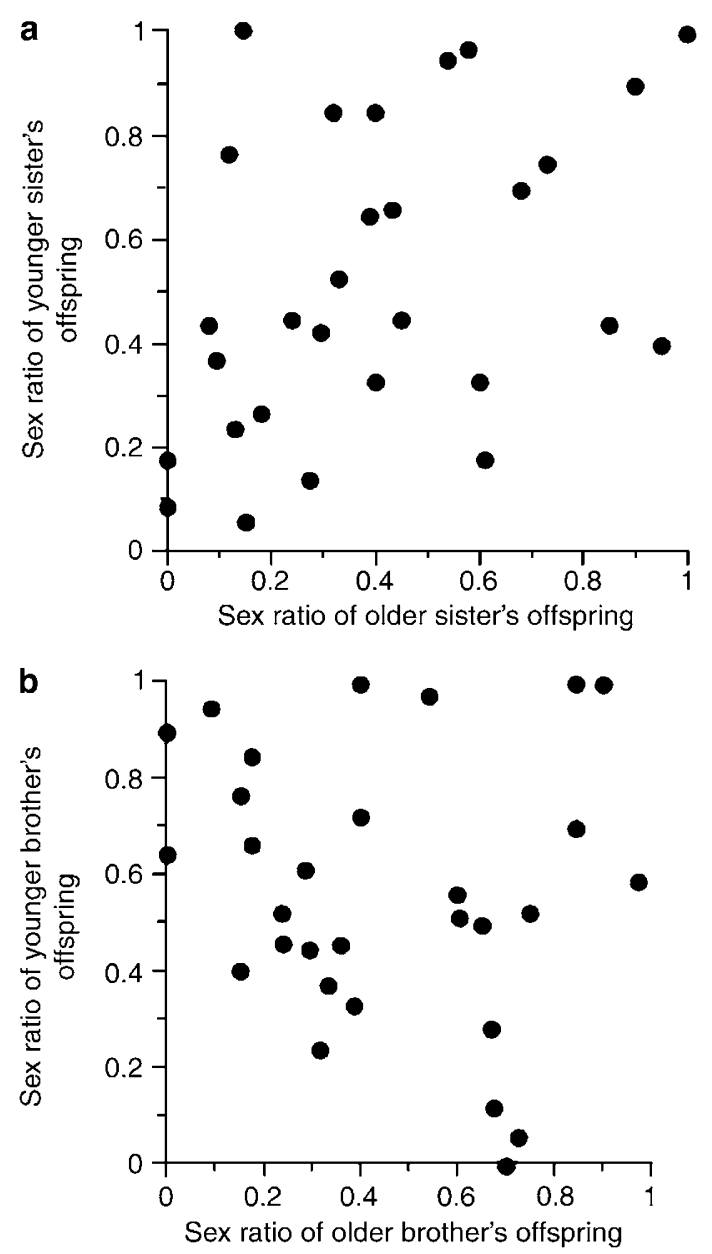

Figure 3 (a) Correlation between sisters in their offspring sex ratios (proportion of males). (b) Correlation between brothers in their offspring sex ratios. For drawing purposes, the sex ratio of the older sibling was taken on the abscissa. relationship for the sex ratio between a mother's siblings and that of her offspring. Secondly, a significant positive correlation was detected in the offspring sex ratios between two sisters. On the other hand, no significant relationships were detected in the brood sex ratios between a father and his offspring, and between two brothers or between the brother and the sister. Although the sex-ratio data were transformed to the underlying $m$-values in this study, a more traditional arcsine-transformation resulted in virtually identical results. The presence of genetic effects on the brood sex ratio is congruent with previous studies reporting high correlations of the sex ratios between full-sib broods (Yusa and Suzuki, 2003) and a lack of any environmental effects (Yusa, 2004b).

Parent-offspring regression has been studied in other organisms showing variable brood sex ratios, such as the parasitic wasp Nasonia vitripennis (Orzack and Gladstone, 1994), the polychaete worm O. labronica (Premoli et al, 1996), and the copepod Tigriopus californicus (Voordouw and Anholt, 2002). Among these, the results for the polychaete worm are especially interesting in that they represent a mirror image of the present results. Premoli et al (1996) found a significant positive relationship for the sex ratios between a father and his offspring, but not between a mother and her offspring. As the most likely mechanism, the authors suggested a heterogametic sex determination imposed by the mother (eg $W$ for female and $\mathrm{Z}$ for male) and modified by minor polygenes of the father. It is doubtful whether such a mechanism can be maintained for a long time, since in the next generation, females with a 'male' genotype ( $\mathrm{ZZ}$ with female modification genes) will appear, and the heterogamety will collapse in subsequent generations.

\section{Genetics of sex-ratio variation}

Although the exact genetics of the sex-ratio variation are difficult to determine, the present data can be used to distinguish among plausible and unlikely models of sexratio variation in $P$. canaliculata. In this section, I discuss three simple genetic systems that could provide possible explanations for the sex-ratio variation, namely cytoplasmic sex factors, parental sex-ratio genes and polygenic sex determination. All genetic variance is assumed to be additive (Yusa, in preparation), and no environmental effects are supposed (Yusa, 2004b). These models are now tested against the present data.

The inheritance of sex-ratio variation through the females but not through the males in this study may suggest the presence of cytoplasmic sex factors. However, the coefficients of the mother-offspring regression and correlation between sisters appeared to be too low to postulate cytoplasmic factors, since such factors would,

Table 1 Expected regression or correlation coefficients of brood sex ratios under various genetic systems with additive genetic variance and no environmental effects

\begin{tabular}{lcccc}
\hline Genetic system & Mother-offspring regression & Father-offspring regression & Correlation between sisters & Correlation between brothers \\
\hline Cytoplasmic sex factors & 1 & 0 & 1 & 0 \\
Sex-ratio genes (biparental) & 0.5 & 0.5 & 0.25 & 0.25 \\
Polygenic sex determination & 0.5 & 0.5 & 0.25 & 0.25 \\
Present data (mean \pm SE) & $0.28 \pm 0.13$ & $0.10 \pm 0.16$ & $0.41 \pm 0.18$ & $-0.13 \pm 0.19$
\end{tabular}


although not always, show an almost perfect inheritance from a mother to her daughters (Table 1). In addition, cytoplasmic factors often act selfishly and lead to femalebiased population sex ratios (Stouthamer et al, 2002), which was not the case for this snail. Furthermore, the possible presence of Wolbachia in the ovary of $P$. canaliculata was preliminarily checked using DNA primers, but the results were negative (H Noda, 1998, personal communication; K Miura, 2002, personal communication). Thus, nuclear genes are more likely.

Nuclear genes are either parental sex-ratio genes or zygotic sex-determining genes. When additive sex-ratio genes with no environmental effects are supposed, parent-offspring regressions are expected to be 0.5 , since each parent is responsible for half the genetic variance of the offspring sex ratio. Likewise, correlations between siblings are expected to be 0.25 , since each of two siblings with a relatedness of 0.5 mates with a different male (Table 1). The results of the current study were very different from these values, and in particular, the lack of paternal effects does not support this interpretation. Sex-ratio genes inherited maternally would show the same inheritance pattern as cytoplasmic factors and hence were not supported by the data, either. Thus, the sex-ratio variation is probably caused by zygotic sexdetermining genes. Further evidence will be reported elsewhere (Yusa, in preparation).

The results also exclude the possibility of simple polygenic sex determination. Under polygenic sex determination without any environmental effects, the coefficients of parent-offspring regressions are 0.5 (Orzack and Gladstone, 1994; Premoli et al, 1996; Voordouw and Anholt, 2002). Correlations in a normal quantitative trait between two siblings are 0.5 when the genetic effects are all additive (Falconer, 1989). Hence, when these siblings are mated to different partners, the correlations in the sex ratio between the offspring of two siblings are 0.25 , as is the case for the sex-ratio genes (Table 1). Again, the results of the current study were very different from these values. However, the expected coefficients should be taken with caution, since choosing parents from siblings of biased sex ratios will cause an unintentional selection pressure (Y Suzuki, 2001, personal communication). For instance, choosing a rare male from a brood with a female-biased sex ratio will impose a strong selection pressure toward the equal sex ratio (equivalent to the intensity of selection, i; Falconer, 1989). The expected regression or correlation coefficients incorporating this effect are under investigation. However, the asymmetrical nature of the results between the sexes is not explained, even when this effect is taken into consideration.

Therefore, none of the typical cytoplasmic sex factors, sex-ratio genes or polygenes for sex determination could explain the current results. This may suggest the presence of a more complicated system, such as sexratio or sex-determining polygenes that act nonadditively. Alternatively, it may indicate sex determination by a small number of genes. Unfortunately, parentoffspring regressions and sib correlations such as conducted in this study are not suitable to analyze sex-determining genes that interact with each other to determine the zygote's sex. A more direct experimental design to study sex-determining genes is that each male or female parent is mated to more than one partner and the sex ratios of half-sib broods are compared (Saavedra et al, 1997). The results of such a study, which suggest the involvement of a small number of sex-determining genes in $P$. canaliculata, will be reported soon (Yusa, in preparation).

\section{Acknowledgements}

I thank M Ishizaki, A Kobayashi, M Matsumura, Y Suzuki, K Tanaka, S Urano and T Wada, and other members at KONARC for inspiring discussions, and A Kobayashi and two anonymous referees for valuable comments on the manuscript. I also thank $\mathrm{H}$ Noda and $\mathrm{K}$ Miura for checking the symbiotic bacteria of P. canaliculata.

\section{References}

Bull JJ (1983). Evolution of Sex Determining Mechanisms. Benjamin/Cummings: California.

Bulmer MG, Bull JJ (1982). Models of polygenic sex determination and sex ratio control. Evolution 36: 13-26.

Cowie RH (2002). Apple snails as agricultural pests: their biology, impacts, and management. In: Baker GM (ed) Molluscs as Crop Pests. CABI: Wallingford. pp 145-192.

Falconer DS (1989). Introduction to Quantitative Genetics, 3rd edn. John Wiley and Sons: New York.

Fisher RA (1930). The Genetical Theory of Natural Selection. Clarendon Press: Oxford.

Hardy ICW (ed) (2002). Sex Ratios: Concepts and Research Methods. Cambridge University Press: Cambridge.

Kobayashi A, Tanaka Y, Shimada M (2003). Genetic variation of sex allocation in the parasitoid wasp Heterospilus prosopidis. Evolution 57: 2659-2664.

Orzack SH, Gladstone J (1994). Quantitative genetics of sex ratio traits in the parasitic wasp, Nasonia vitripennis. Genetics 137: 211-220.

Premoli MC, Sella G, Berra GP (1996). Heritable variation of sex ratio in a polychaete worm. J Evol Biol 9: 845-854.

Procter HC (1996). Sex-ratios and chromosomes in water mites (Hydracarina). In: Mitchell $\mathrm{R}$ et al (eds) Acarology IV Proceedings. Ohio Biological Survey: Ohio. pp 441-445.

Roff DA (1997). Evolutionary Quantitative Genetics. Chapman \& Hall: New York.

Saavedra C, Reyero MI, Zouros E (1997). Male-dependent doubly uniparental inheritance of mitochondrial DNA and female-dependent sex-ratio in the mussel Mytilus galloprovincialis. Genetics 145: 1073-1082.

Sokal R, Rohlf FJ (1981). Biometry, 3rd edn. Freeman: New York.

Stouthamer R, Hurst GDD, Breeuwer JAJ (2002). Sex ratio distorters and their detection. In: Hardy ICW (ed) Sex Ratios: Concepts and Research Methods. Cambridge University Press: Cambridge. pp 195-215.

Voordouw MJ, Anholt BR (2002). Heritability of sex tendency in a harpacticoid copepod, Tigriopus californicus. Evolution 56: 1754-1763.

Werren JH, Beukeboom WB (1998). Sex determination, sex ratios, and genetic conflict. Ann Rev Ecol Syst 29: 233-261.

Wilson K, Hardy ICW (2002). Statistical analysis of sex ratio: an introduction. In: Hardy ICW (ed) Sex Ratios: Concepts and Research Methods. Cambridge University Press: Cambridge. pp 48-92.

Yanagimachi R (1961). Studies on the sexual organization of the Rhizocephala. III. The mode of sex-determination in Peltogasterella. Biol Bull 120: 272-283.

Yusa Y (2004a). Inheritance of colour polymorphism and the pattern of sperm competition in the apple snail Pomacea canaliculata (Gastropoda: Ampullariidae). J Moll Stud 70: 43-48. 
Yusa Y (2004b). Brood sex ratio in the apple snail Pomacea canaliculata (Gastropoda: Ampullariidae) in determined genetically and not by environmental factors. J Moll Stud 70: 269-275. Yusa Y, Sugiura N, Wada T (2005). Predatory potential of freshwater animals on an invasive agricultural pest, the apple snail Pomacea canaliculata (Gastropoda: Ampullariidae), in southern Japan. Biol Invasions, in press.

Yusa Y, Suzuki Y (2003). A snail with unbiased population sex ratios but highly biased brood sex ratios. Proc $R$ Soc Lond $B$ 270: $283-287$. 